\title{
Biocomplementation of SVE to achieve clean-up goals in soils contaminated with toluene and xylene
}

\author{
António Alves Soares \& Maria Teresa Pinho \& José \\ Tomás Albergaria \& Valentina Domingues \& Maria da \\ Conceição Alvim-Ferraz \& \\ Cristina Delerue-Matos
}

\begin{abstract}
Soil vapor extraction (SVE) and bioremedia- tion (BR) are two of the most common soil remediation technologies. Their application is widespread; however, both present limitations, namely related to the efficien- cies of SVE on organic soils and to the remediation times of some BR processes. This work aimed to study the combination of these two technologies in order to verify the achievement of the legal clean-up goals in soil remediation projects involving seven different simulated soils separately contaminated with toluene and xylene. The remediations consisted of the application of SVE followed by biostimulation. The results show that the combination of these two technologies is effective and manages to achieve the clean-up goals imposed by the Spanish Legislation. Under the experimental conditions used in this work, SVE is sufficient for the remediation of soils, contaminated separately with toluene and xylene, with organic matter contents (OMC) below $4 \%$. In soils with higher OMC, the use of BR, as a complementary technology, and when the concentration of contaminant in the gas phase of the soil reaches values near $1 \mathrm{mg} / \mathrm{L}$, allows the achievement of the clean-up goals. The OMC was a key parameter because it hindered SVE due to adsorption phenomena but en- hanced the BR process because it acted as a microor- ganism and nutrient source.
\end{abstract}

Keywords Toluene $\cdot$ Xylene $\cdot$ Soil vapor extraction Bioremediation $\cdot$ Organic matter $\cdot$ Water content . Remediation time

Introduction

Soil vapor extraction (SVE) is one of the most used soil remediation technologies. being applied to contamina- tions with volatile compounds that are located in the unsaturated zone of the soil (USEPA 2010). Among the most popular target contaminants, chlorinated hydrocar- bons (such as trichloroethylene (TCE) and perchloro- ethylene) and petroleum hydrocarbons (such as the group of contaminants constituted by benzene, toluene, ethylbenzene, and xylene (BTEX)) can behighlighted. This technology promotes an air movement in the soil matrix, which desorbs and extracts the contaminants from the soil and transfers them to the exterior where air treatment units remove/destroy them (Suthersan 1999). This technology presents as major advantages 
the relative low cost and the relative simplicity of the installation of the equipment and its operation (USEPA 1997). Numerous works showed that this technology can rapidly and efficiently remove several types of contaminants from sites with distinct soil properties and different operating conditions (Alvim-Ferraz et al. 2006; Albergaria et al. 2008; Yin et al. 2011). However, SVE has several limitations that reduce its overall efficiency and prolong the remediation process, turning it into a more time-consuming and consequently more expensive technology. Recent works showed that in soils with high organic matter contents, where adsorption effects are much stronger, the remediation efficiency decreases to levels that could jeopardize the achievement of the defined clean-up goals and, as a consequence, the remediation process (Albergaria et al. 2008; Qin et al. 2010). Caroll et al. (2012) stated that contaminations located in lower-permeability areas of the soil are difficult to remediate due to mass transfer process limitations, clearly affecting the removal effectiveness. These untreated areas can act as a source of contamination to previously cleaned areas of the site, requiring supplementary treatment. Soil water content can also influence, but at a lower extend, the remediation process due to the impact that it induces on the porosity of the soil and on the dissolution of some contaminants, such as trichloroethylene (TCE) (Yoon et al. 2003; Albergaria et al. 2012). In conclusion, it is clear that under certain conditions, SVE is extremely efficient and can, by itself, achieve the pre-defined clean-up goals. However, there are situations where it is indispensable to use complementary actions/technologies in order to successfully finish the remediation.

Bioremediation (BR) is one of the remediationtechnologies that, because of its characteristics, are easily taken into account. This technology can be defined as the biologically catalyzed treatment of organic contaminants and can be used in different methodologies such as bioaugmentation (BA) and biostimulation (BS) (Moliterni et al. 2012). BA uses an inoculated microbiota that has special affinity for the target contaminant (Gentry et al. 2004); BS, the most usual, aims the enhancement of the activity of the autochthonous microorganisms by adjustment of the operating conditions that affect the bioremediation process the most, namely pH and moisture content (Moliterni et al. 2012). There are several works proving the success of these two methodologies, such as in the treatment using BS of a mazut-contaminated soil (Beskoski et al. 2011) or a hydrocarbon-contaminated subsoil of a metalworking plant (Menendez-Vega et al. 2007), and the degradation of chlorpyrifos in soil through plasmid-mediated bioaugmentation (Zhang et al.2012).

However, as well as SVE, BR presents operational limitations that hinder the remediation process and, consequently, its efficiency. Physical and chemical properties of the soils such as the amount of macronutrients of the soil (Braddock et al. 1997), salinity (Qin et al. 2012), and water content (Jacques et al. 2010) influence the degradation rate and, consequently, the process efficiency (Atlas and Bartha 1998). Furthermore, the concentration of the contaminants and their properties (structure, solubility, toxicity, among others) will control the availability and biodegradability of the contaminants, influencing the remediation. Experiments performed in different soils contaminated with ethylbenzene showed that microbial activity was inhibited when ethylbenzene concentrations were higher than $438 \mathrm{mg} / \mathrm{kg}_{\text {soil }}$, restraining the remediation and impeding the achievement of the clean-up goals (Soares et al. 2012). Contaminants with low water solubility have limited availability to microorganisms, which represents a potential problem for bioremediation processes (Cameotra and Makkar 2010).

Attending to the potential and limitations of both SVE and BR, they can be easily and efficiently combined by exploiting, in a first stage, the capacity of SVE to extract high amounts of contaminants in a short period of time (consequently decreasing the soil toxicity), and in a second stage, the low costs of BR to reach the clean-up goals. However, it is not clear in what situations SVE is sufficient, when it requires complementary BR, and at what point BR should be applied. In previous works performed in distinct soils contaminated separately with benzene and ethylbenzene, SVE and BR were successfully combined, achieving the clean-up goals in $100 \%$ of the cases for soils contaminated with benzene and $89 \%$ for soils contaminated with ethylbenzene (Soares et al. 2010, 2012). A wider view and knowledge of this subject is achieved by experimenting and studying othercontaminants.

Other technologies such as incineration and thermal desorption are also used for the remediation of soils contaminated with this kind of contaminants (namely BTEX), achieving efficiencies above $95 \%$. However, these thermal treatments are very expensive and require heavy equipment (USEPA 2010). 
The objectives of this work were to study the combination of SVE and BR in order to verify the achievement of the legal clean-up goals in soil remediation projects, involving seven different simulated soils which are separately contaminated with toluene and xylene, and to evaluate the impact of the soil properties (organic matter and moisture contents) on the SVE-BR combination.

\section{Experimental}

Reagents

Toluene and xylene were purchased from Merck. Mineral medium (containing $\mathrm{CaCl}_{2} \cdot \mathrm{H}_{2} \mathrm{O}, \mathrm{MgSO}_{4}$, and $\left.\left(\mathrm{NH}_{4}\right)_{2} \mathrm{SO}_{4}\right)$ was prepared according to Kelly et al. (1994).

Apparatus

A gas chromatograph (Shimadzu GC-2010) equipped with a flame ionization detector and a TRB 35 NF-2670 (30 $\mathrm{m} \times 0.53 \mathrm{~mm} \times 3 \mu \mathrm{m}$ ) column was used to monitor the SVE and BR processes. The injectors and the detectors were set at $250{ }^{\circ} \mathrm{C}$, and the column was maintained at $200{ }^{\circ} \mathrm{C}$ throughout the analysis. Helium at $30 \mathrm{~cm}^{3} / \mathrm{min}$ was used as the carrier gas. Flame gases were air $\left(400 \mathrm{~cm}^{3} / \mathrm{min}\right)$ and hydrogen $\left(40 \mathrm{~cm}^{3} / \mathrm{min}\right)$. Chromatographic data were recorded and treated using GC Solution Analysis software version 2.30.00 (Shimadzu).

External standard calibration using eight standards was used for the quantification of toluene and xylene. The working concentration ranges were $0.7-35 \mathrm{~g} / \mathrm{m}^{3}$ for toluene and $0.3-41 \mathrm{~g} / \mathrm{m}^{3}$ for xylene. The calibration curves had correlation coefficients between 0.9979 and 0.9995 .

\section{Soil preparation and characterization}

A sandy and a humic soil were collected in order to prepare soils with different water and organic matter contents. The sandy soil was collected at a depth of $1 \mathrm{~m}$ from different places on a beach, and the humic soil was collected in a forest at a depth of 2-5 cm. Both samples were obtained from the region around Porto, Portugal; after the collection, they were stored in appropriate vessels. These soils were the same as the ones used in previous works (Soares et al. 2010, 2012).
The soils were characterized by determining the following properties: (a) apparent density (ASTM D4531-86), (b) particle density (DIN 18124), (c) pH (US-EPA 9045 d), (d) SWC (ASTM D 2216), and (e) NOMC (Wakley-Black method). Porosity was calculated based on apparent soil density and particle density. The results of the characterization of the soils are presented in Soares et al. (2010). The soils were identified as $\mathrm{P}_{a, b}$, where the letter " $\mathrm{P}$ " indicates that the soil was prepared and the letters " $a$ " and " $b$ " indicate the contents of water and organic matter, respectively.

\section{Calculation of the SVE efficiency}

The performance of the SVE process was evaluated according to the value of the concentration of the contaminant that remained in the soil after the treatment. This value was calculated using the methodology described in Alvim-Ferraz et al. (2006). Equilibrium experiments were performed in several prepared stainless steel columns (height $=37 \mathrm{~cm}$, internal diameter $=10 \mathrm{~cm}$ ) containing different soils with distinct levels of contamination. After the establishment of equilibrium inside the columns, the concentration of the contaminant in the gas phase of the soil was determined by gas chromatography. Through data fitting, a mathematical function relating the concentration of the contaminant in the gas phase of the soil and the level of contamination was obtained for each soil. Using this mathematical tool and with the measured concentration of the contaminant in the gas phase, it was possible to calculate the amount of contaminant remaining in the soil after each SVE and, subsequently, the efficiency of the process.

\section{Soil vapor extraction experiments}

The SVE experiments were performed in the stainless steel columns described in the previous section. The preparation of these columns consisted of (1) introduction of the soil in the column, (2) soil contamination with the selected contaminant (toluene or xylene), (3) equilibrium settling, and (4) determination of the concentration of the contaminant in the gas phase of the soil. The soil was introduced in the column in $500 \mathrm{~g}$ fractions, and after the introduction of each fraction, the soil was compacted in a way that guaranteed similar soil porosities in all studies. The soil contamination was achieved by the introduction of $1.0 \mathrm{~g}$ of the contaminant at the top of the soil column. The soil was then left isothermally at 
$23{ }^{\circ} \mathrm{C}$. To evaluate if the equilibrium was reached, the concentration of the contaminant in the soil gas phase was monitored over time at four different heights of the column. When the obtained concentrations at the four sampling ports were similar (deviation below $5 \%$ ), equilibrium was considered to have been reached, which happened within $48 \mathrm{~h}$ in all cases. After this, the column was connected to the laboratorial installation to perform the SVE experiments.

To start the SVE experiment, a vacuum pump was switched on, allowing a controlled (monitored by a flow meter) airflow to percolate through the soil column and then through a sampling system where gas emissions were collected for gas chromatography analysis. An activated charcoal recipient was placed before the pump for its protection and to avoid atmospheric contamination. The remediation process was considered final when the concentration of the contaminant in the gas phase was below $1.0 \mathrm{mg} / \mathrm{L}$ (Soares et al. 2010). The time needed to reach this level was considered the SVE remediation time. The column was then left again isothermally at $23^{\circ} \mathrm{C}$ to achieve a new equilibrium, and the amount of the contaminant remaining in the soil was calculated.

\section{Bioremediation experiments}

According to the results presented in previous works, the native microorganisms of the soils used in this work showed to be the ones with the best degradation rates; this fact supported the use of these microorganisms in the BR experiments (Soares et al. 2010, 2012). These experiments were performed in those cases (soils $\mathrm{P}_{2,14}$ and $\mathrm{P}_{4,24}$ ), where after the application of SVE, the soils presented contamination levels above the legal limits. The preparation of the soils for the BR experiments basically consisted of the addition of substrate and water. No external oxygen supply was used during the process because there was enough air in the headspace of the columns. The BR was considered finished when the concentration of toluene and xylene in the soil reached the legal limit $(100 \mathrm{mg} / \mathrm{kg}$ for both contaminants). To establish the concentration of the contaminants in the gas phase of the soil corresponding to this limit, two columns were prepared with sterile soil $\mathrm{P}_{2,14}$, each one contaminated separately with $100 \mathrm{mg} / \mathrm{kg}$ of toluene and xylene. A similar procedure was followed for soil $\mathrm{P}_{4,24}$. The sterilization was performed by autoclaving. After the establishment of the equilibrium in the column, the concentrations of toluene and xylene in the gas phase of the soil were determined and used as the end points for the BR experiments. The BR time was defined as the time required to reach these concentrations. The sum of the SVE remediation time and the BR time was defined as the global remediation time.

Results

Soil vapor extraction experiments

SVE was performed in seven different soils with different organic matter $(0,4,14$, and $24 \%)$ and moisture $(0,2,3$, and $4 \%)$ contents using four distinct airflow rates $(2,5,10$, and $20 \mathrm{~L} / \mathrm{h})$. At the end of each remediation experiment, the remediation time and the amount of contaminant that remained in the soil after the treatment were calculated. The results of the SVE performed in soils contaminated with toluene and xylene are presented in Tables 1 and 2, respectively. Relative deviations $(n=5)$ lower than $5 \%$ were observed for both toluene and xylene. Considering the legal limits for toluene and xylene under the Spanish Legislation (100 mg/kg for both contaminants), the clean-up goals were considered (a) achieved when the concentration of the contaminant after the SVE was below that limit, (b) nearly achieved when the concentration of the contaminant was between 100 and $150 \mathrm{mg} / \mathrm{kg}$, and (c) not achieved if the concentration was higher than $150 \mathrm{mg} / \mathrm{kg}$.

The SVE experiments in which the clean-up goals were achieved (all except for soil $\mathrm{P}_{4,24}$ ) were considered successful, and the soils were defined as noncontaminated (according to the Spanish Legislation). In this set of experiments, no case was obtained with a remaining concentration between 100 and $150 \mathrm{mg} / \mathrm{kg}$. In the few cases where SVE did not manage to achieve the clean-up goals, complementary actions had to be applied, in this work, bioremediation (see next section).

The results show that SVE is extremely efficient for the remediation of sandy soils contaminated with toluene and is independent of the moisture content. This is closely related with the low organic matter content and high porosity of these type of soils, which are not able to significantly adsorb the contaminants, hence concentrating them in the gas phase of the soil where 
Table 1 Results obtained in the SVE experiments in soils contaminated with toluene

\begin{tabular}{|c|c|c|c|c|c|}
\hline Soil & Experiment ID & Flow rate $(\mathrm{L} / \mathrm{h})$ & $\begin{array}{l}\text { Remediation } \\
\text { time (h) }\end{array}$ & $\begin{array}{l}\text { Level of } \\
\text { contamination } \\
\text { in the end }(\mathrm{mg} / \mathrm{kg})\end{array}$ & $\begin{array}{l}\text { Clean-up } \\
\text { efficiency }(\%)\end{array}$ \\
\hline \multirow[t]{4}{*}{$\mathrm{P}_{0,0}$} & 1 & 18 & 2.9 & 11.6 & 95.8 \\
\hline & 2 & 10 & 4.2 & 10.0 & 96.3 \\
\hline & 3 & 6.4 & 5.7 & 10.1 & 96.2 \\
\hline & 4 & 2.0 & 8.1 & 10.4 & 96.2 \\
\hline \multirow[t]{4}{*}{$\mathrm{P}_{2,0}$} & 5 & 18 & 2.5 & 24.2 & 90.3 \\
\hline & 6 & 10 & 5.2 & 25.8 & 89.7 \\
\hline & 7 & 6.2 & 7.5 & 22.9 & 90.7 \\
\hline & 8 & 1.9 & 9.2 & 21.1 & 90.5 \\
\hline \multirow[t]{4}{*}{$\mathrm{P}_{3,0}$} & 9 & 18 & 2.6 & 15.8 & 93.7 \\
\hline & 10 & 9.9 & 5.5 & 11.8 & 94.8 \\
\hline & 11 & 6.5 & 7.2 & 9.1 & 96.2 \\
\hline & 12 & 3.0 & 13.1 & 10.0 & 95.7 \\
\hline \multirow[t]{4}{*}{$\mathrm{P}_{4,0}$} & 13 & 18 & 2.9 & 24.5 & 90.2 \\
\hline & 14 & 10 & 5.5 & 22.0 & 90.7 \\
\hline & 15 & 6.8 & 7.0 & 21.1 & 91.0 \\
\hline & 16 & 2.5 & 13.9 & 20.3 & 91.2 \\
\hline \multirow[t]{4}{*}{$P_{1,4}$} & 17 & 18 & 3.8 & 90.1 & 72.2 \\
\hline & 18 & 9.2 & 8.6 & 41.4 & 87.8 \\
\hline & 19 & 4.0 & 20.1 & 28.5 & 91.1 \\
\hline & 20 & 1.6 & 27.3 & 6.32 & 96.3 \\
\hline \multirow[t]{4}{*}{$P_{2,14}$} & 21 & 17 & 6.5 & 94.6 & 75.1 \\
\hline & 22 & 10 & 9.4 & 77.4 & 80.2 \\
\hline & 23 & 4.4 & 36.6 & 63.4 & 84.7 \\
\hline & 24 & 2.0 & 46.7 & 53.9 & 87.9 \\
\hline \multirow[t]{4}{*}{$P_{4,24}$} & 25 & 17 & 7.1 & 392 & 62.7 \\
\hline & 26 & 9.9 & 20.0 & 361 & 62.8 \\
\hline & 27 & 4.7 & 52.3 & 336 & 66.9 \\
\hline & 28 & 2.5 & 67.0 & 319 & 73.5 \\
\hline
\end{tabular}

they are easily extracted (Albergaria et al. 2010). The longest remediations were observed for soils with higher water contents because of the decrease of the soil porosity which hindered the movement of air through the soil. Considering that it is desirable that the remediation is as short as possible, the use of the highest flow rate $(20 \mathrm{~L} / \mathrm{h})$ achieved the legal limit faster and with a lower cost than the lower airflow rates. This is also supported by other works such as described by Albergaria et al. (2008) and Jiao et al. (2011).

The remediation of soils with higher organic matter contents $\left(\mathrm{P}_{1,4}, \mathrm{P}_{2,14}\right.$, and $\left.\mathrm{P}_{4,24}\right)$ showed to be generally more time consuming and less efficient. The presence of organic matter in the soil hinders the extraction process because it adsorbs the contaminant, reducing its mobility and its subsequent extraction. All the experiments performed with soils $\mathrm{P}_{1,4}$ and $\mathrm{P}_{2,14}$ managed to reach the clean-up goals, but when higher airflow rates were used, higher remaining concentrations of the contaminant in the soil (near the legal limit of $100 \mathrm{mg} / \mathrm{kg}$ ) were obtained. The use of lower airflow rates will guarantee that the process occurs in equilibrium conditions and that slow diffusion effects are avoided (Albergaria et al. 2010), enhancing the remediation. Table 1 clearly proves this effect, showing that the reduction of the airflow rates from the highest rate (around $17 \mathrm{~L} / \mathrm{h}$ ) to the lowest rate (around $2.0 \mathrm{~L} / \mathrm{h}$ ) resulted in a decrease of the toluene concentration from 19 to $93 \%$. Finally, soil $\mathrm{P}_{4,24}$ clearly showed 
Table 2 Results obtained in the SVE experiments in soils contaminated with xylene

\begin{tabular}{|c|c|c|c|c|c|}
\hline Soil & Experiment ID & Flow rate $(\mathrm{L} / \mathrm{h})$ & $\begin{array}{l}\text { Remediation } \\
\text { time (h) }\end{array}$ & $\begin{array}{l}\text { Level of contamination } \\
\text { in the end }(\mathrm{mg} / \mathrm{kg})\end{array}$ & $\begin{array}{l}\text { Clean-up } \\
\text { efficiency }(\%)\end{array}$ \\
\hline \multirow[t]{4}{*}{$P_{0,0}$} & 29 & 18 & 2.1 & 22.8 & 90.4 \\
\hline & 30 & 9.9 & 5.4 & 14.7 & 94.6 \\
\hline & 31 & 5.4 & 8.0 & 15.7 & 94.1 \\
\hline & 32 & 2.3 & 11.2 & 5.6 & 97.7 \\
\hline \multirow[t]{3}{*}{$\mathrm{P}_{2,0}$} & 33 & 17 & 4.6 & 24.3 & 92.1 \\
\hline & 34 & 9.9 & 7.8 & 28.5 & 90.3 \\
\hline & 35 & 6.5 & 14.0 & 18.8 & 93.0 \\
\hline \multirow[t]{4}{*}{$\mathbf{P}_{3,0}$} & 36 & 18 & 5.3 & 5.0 & 96.7 \\
\hline & 37 & 10 & 8.0 & 3.1 & 97.8 \\
\hline & 38 & 5.0 & 14.3 & 2.7 & 98.0 \\
\hline & 39 & 1.9 & 17.0 & 3.4 & 97.6 \\
\hline \multirow[t]{4}{*}{$\mathrm{P}_{4,0}$} & 40 & 18 & 5.1 & 2.4 & 98.0 \\
\hline & 41 & 8.7 & 6.6 & 2.4 & 98.0 \\
\hline & 42 & 5.3 & 12.1 & 3.7 & 97.3 \\
\hline & 43 & 2.3 & 15.9 & 6.9 & 95.6 \\
\hline \multirow[t]{4}{*}{$P_{1,4}$} & 44 & 18 & 5.2 & 98.2 & 65.8 \\
\hline & 45 & 10 & 19.3 & 57.7 & 78.4 \\
\hline & 46 & 4.3 & 51.5 & 61.1 & 78.5 \\
\hline & 47 & 2.2 & 63.0 & 63.6 & 79.6 \\
\hline \multirow[t]{4}{*}{$P_{2,14}$} & 48 & 18 & 9.0 & 306 & 45.5 \\
\hline & 49 & 10 & 20.0 & 209 & 62.5 \\
\hline & 50 & 4.9 & 44.0 & 187 & 66.5 \\
\hline & 51 & 2.4 & 93.6 & 122 & 75.6 \\
\hline \multirow[t]{4}{*}{$\mathrm{P}_{4,24}$} & 52 & 18 & 11.3 & 477 & 43.4 \\
\hline & 53 & 8.9 & 26.2 & 328 & 61.2 \\
\hline & 54 & 4.3 & 60.0 & 294 & 65.1 \\
\hline & 55 & 2.0 & 95.3 & 125 & 75.1 \\
\hline
\end{tabular}

the negative impact of organic matter on the SVE process by turning it inefficient, not capable to achieve the legal limits, and requiring complementary treatment. Even using lower airflow rates, the efficiency is still not sufficient.

In conclusion, and for humic soils contaminated with toluene, it can be stated that for soils with organic matter contents lower than $14 \%$, SVE achieves concentrations below $100 \mathrm{mg} / \mathrm{kg}$, but even for these soils, it is advisable to use airflow rates between 2 and $5 \mathrm{~L} / \mathrm{h}$ in order to guarantee the remediation's success.

Table 2 presents the results obtained in the SVE experiments in soils contaminated with xylene. The observed behavior is similar to the experiments performed with toluene. However, in this case, the lower vapor pressure of xylene negatively influenced the SVE process, limiting the vaporization rate of the contaminant, restraining the amount that is in the gas phase of the soil and, as a consequence, decreasing the amount that can be easily removed through SVE.

As in the experiments with toluene, SVE showed to be appropriate to achieve the clean-up goals in all experiments with sandy soils; however, when humic soils were tested, different results were obtained. The difficulties to reach the legal limits already occurred in soil $\mathrm{P}_{2,14}$ even with the lowest airflow rate, where the clean-up goal was nearly achieved (as in the experiment with the lower airflow rate in soil $\left.\mathrm{P}_{4,24}\right)$. For these cases, it is advisable to use a pulsed SVE to remove the remaining amount; however, for the experiments shown in Table 1, no such case was observed. The use of this SVE variation showed good results in other works compared with traditional SVE (Kaleris and Croise 1997; Kirtland and Aelion 2000) 
Fig. 1 Bioremediation experiments in soil $\mathrm{P}_{2,14}$ contaminated with xylene

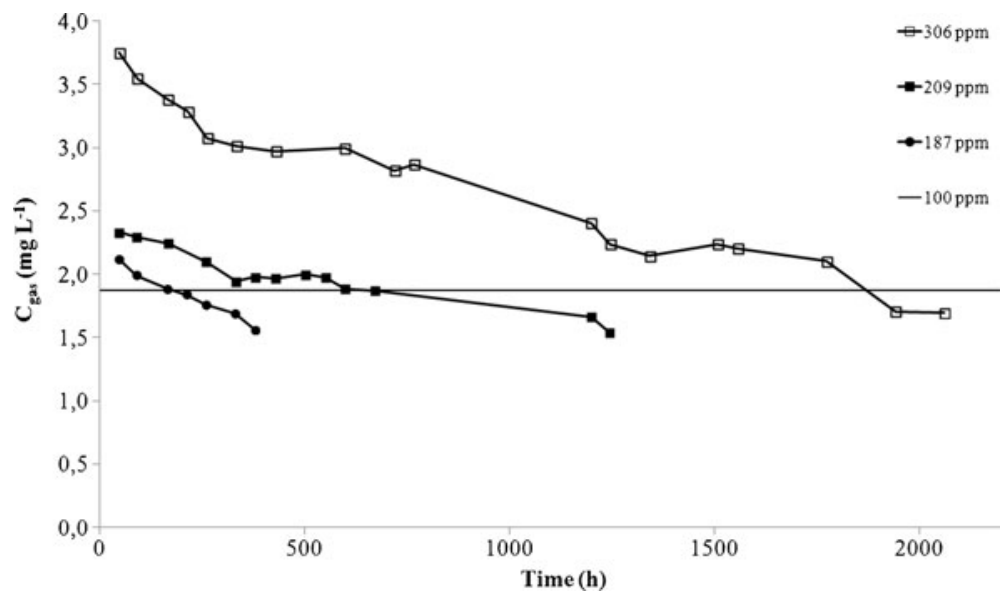

and can avoid the application of a new technology. The pauses in the pulsed SVE process force a new redistribution of the contaminant through all the soil phases, leading to mass transfer from the solid phase to the gas phase of the soil. This will increase the mobility and availability of the contaminant, increase the amount of contaminant that can be extracted when SVE restarts, and consequently achieve better remediation efficiencies (Kirtland and Aelion 2000).

For the treatment of the two organic soils with the highest organic matter content, complementary treatment is required. Comparing the results of Tables 1 and 2, it can be concluded that the SVEs performed in soils contaminated with xylene were more time consuming. This behavior is related to the lower vapor pressure of xylene and to the higher tendency of xylene to adsorb on the organic matter of the soil, hindering its mobility and capacity to be extracted.
Comparing the contamination levels at the end of the remediation, it can be concluded that significant differences were only found in the experiments using humic soils, where xylene was not generally removed to the same extent as toluene. The exceptions are the tests performed in soil $\mathrm{P}_{4,24}$, using the lowest airflow rates, where the best efficiencies were observed for soils contaminated with xylene. Similarly to the experiments with toluene, and aiming the identification of the best remediation conditions, it can be suggested that SVE should be performed with low airflow rates (between 2 and $5 \mathrm{~L} / \mathrm{h}$ ).

\section{Bioremediation experiments}

According to previous works (Soares et al. 2010, 2012), the native microbial consortium of the humic soil used in this work showed to be as efficient to degrade the contaminants as the specific degrading
Fig. 2 Bioremediation experiments in soil $\mathrm{P}_{4,24}$ contaminated with xylene

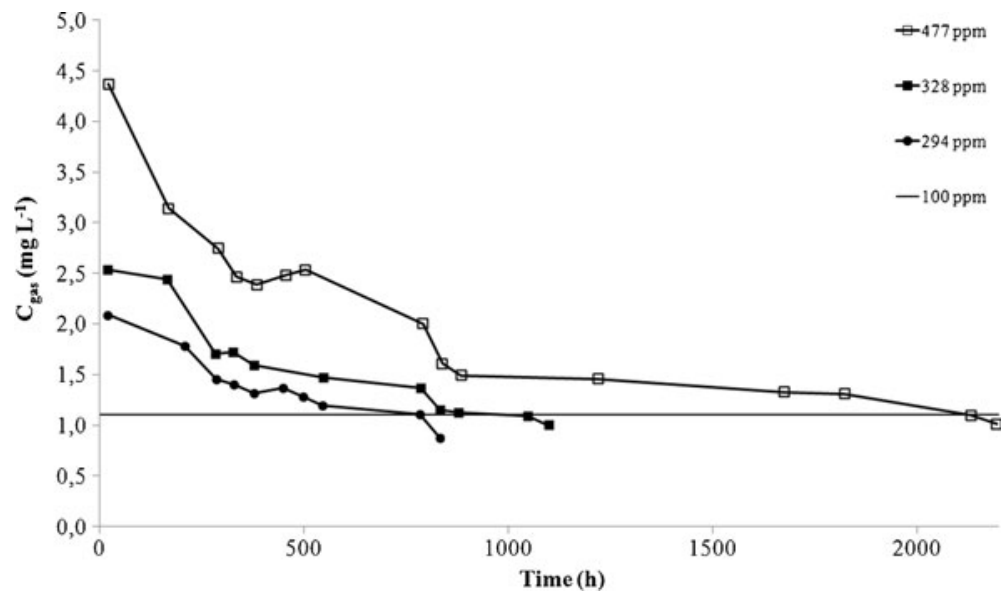


Table 3 Global remediation time for the experiments of SVE complemented with BR

\begin{tabular}{llrll}
\multirow{2}{*}{$\begin{array}{c}\text { Experiment ID Level of contamination } \\
(\mathrm{mg} / \mathrm{kg})\end{array}$} & \multicolumn{3}{c}{ Remediation time (h) } \\
\cline { 3 - 5 } & & SVE & BR & Global \\
\hline 25 & 392 & 7.1 & 1,563 & 1,570 \\
26 & 361 & 20.0 & 740 & 760 \\
27 & 336 & 52.3 & 654 & 706 \\
28 & 319 & 67.0 & 356 & 423 \\
48 & 306 & 9.0 & 1,872 & 1,881 \\
49 & 209 & 20.0 & 677 & 697 \\
50 & 187 & 44.0 & 178 & 222 \\
52 & 477 & 11.3 & 2,132 & 2,143 \\
53 & 328 & 26.2 & 1,043 & 1,069 \\
54 & 294 & 60.0 & 786 & 846 \\
\hline
\end{tabular}

microorganisms inoculated to the tested soil. Based on this, the native microorganisms were used to avoid the introduction of exogenous species in the soil, which is a controversial action because in some cases, predation by protists or the competition with autochthonous microorganisms for electron acceptors or nutrients can occur, hindering the bioremediation process (El Fantroussi and Agathos 2005). Based on the results presented in Tables 1 and 2, the experiments that require complementary treatment, with bioremediation, are the ones identified with the numbers 25 to 28,48 to 50 , and 52 to 54, and correspond to tests performed with soils $\mathrm{P}_{2,14}$ (contaminated with xylene) and $\mathrm{P}_{4,24}$ (contaminated separately with toluene and xylene).

The results of the BR experiments performed with soils $\mathrm{P}_{2,14}$ and $\mathrm{P}_{4,24}$ contaminated with xylene (experiments 48 to 50 and 52 to 54 , respectively) are presented in Figs. 1 and 2, respectively. In Table 3, the global remediation times (the sum of the SVE and BR times) for all the experiments involving SVE complemented with BR are presented. Four other bioremediation experiments (two with toluene and two with xylene) were repeated, and a relative deviation lower than $8 \%$ was observed.

Figures 1 and 2 show that all the BR experiments performed with the soils contaminated with xylene managed to achieve the legal limits for this contaminant $(100 \mathrm{mg} / \mathrm{kg})$, proving that $\mathrm{BR}$ is an effective remediation technology that can complement SVE in a simple and economic way. As expected, higher contamination required longer bioremediation; the BR times took up $>89 \%$ of the global remediation time. Comparing the results of the experiments performed in soils $\mathrm{P}_{2,14}$ and $\mathrm{P}_{4,24}$ with similar contaminations (306 and $294 \mathrm{mg} / \mathrm{kg}$ ), a lower bioremediation time was observed for the soil with the highest organic matter content. These results are in agreement with Soares et al. (2010, 2012) and Macci et al. (2012). This indicates that for SVE experiments, the organic matter content has a negative impact on the remediation process, but when it is complemented with $\mathrm{BR}$, this parameter represents a positive factor leading to faster remediations. This is proven by the results presented in Table 1; experiments after SVE that were the most time consuming became the fastest ones.

It should be highlighted that contrary to what occurred in the BR experiments with ethylbenzene (Soares et al. 2012), no inhibition behavior was observed in the experiments performed with xylene. Figure 3 presents the results of the BR experiments performed with soil $\mathrm{P}_{2,14}$ contaminated with toluene.
Fig. 3 Bioremediation experiments in soil $\mathrm{P}_{4,24}$ contaminated with toluene

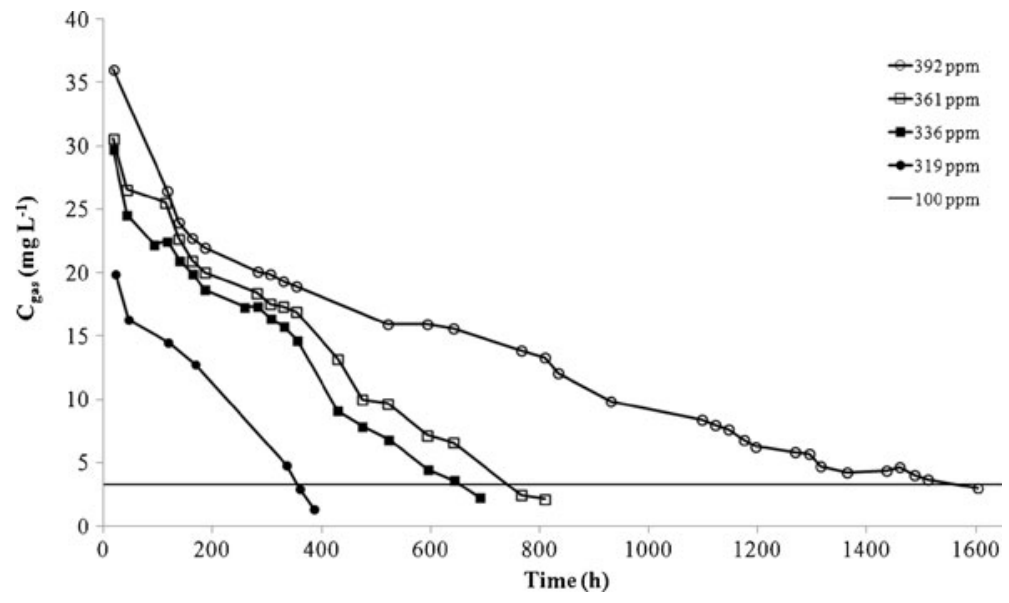


The curves corresponding to the contamination levels 319, 336, and $361 \mathrm{mg} / \mathrm{kg}$ showed similar slopes, while the last curve showed a less accentuated slope. This could indicate that some inhibition occurs at contaminations higher than $361 \mathrm{mg} / \mathrm{kg}$, turning the process into a more time-consuming one. Comparing the results of these experiments with those obtained with soils contaminated with xylene, for the same soil $\left(\mathrm{P}_{4,24}\right)$ and similar contaminations (328 and 319 or $336 \mathrm{mg} / \mathrm{kg}$ for xylene and toluene, respectively), it is possible to conclude that toluene is easily degraded. The time required to reach the clean-up goal in the experiment with xylene was $1,043 \mathrm{~h}$, while for toluene, this was achieved between 356 and $654 \mathrm{~h}$.

In conclusion, BR is a low-cost and efficient technology to complement SVE in the remediation of soils contaminated separately with toluene and xylene. This technology should be applied when the concentrations of the contaminants in the extracted flow reach low values (below $1 \mathrm{~g} / \mathrm{m}^{3}$ ). According to the obtained results, the native microorganisms of the soil can present some inhibition when concentrations of toluene are higher than $336 \mathrm{mg} / \mathrm{kg}$. To prevent this occurrence, pulsed SVE should be used to decrease the contamination levels below $336 \mathrm{mg} / \mathrm{kg}$.

\section{Conclusions}

The results presented in this work allow the conclusion that the combination of SVE with BR is an efficient strategy for the remediation of soils contaminated with toluene or xylene. For sandy soils with different water contents and for organic soils with organic matter contents below $4 \%$ (for xylene) and $14 \%$ (for toluene), SVE is sufficient to achieve the legal limits imposed by the Spanish Legislation. For these cases, low airflow rates ( 2 to $5 \mathrm{~L} / \mathrm{h}$ ) should be used to assure good extraction conditions and higher efficiencies. For the other soils (with higher organic matter content), SVE should be complemented with BR to complete the remediation process.

The results also show that organic matter content hindered the SVE process, making it more time and energy consuming because of the capacity of the organic matter to adsorb the contaminant. However, organic matter content had an opposite effect on BR. Here, the capacity of the organic matter to house microorganisms potentiates the microbial activity of the soil, hence increasing the degradation capacity.

\section{References}

Albergaria, J. T., Alvim-Ferraz, M. D. M., \& Delerue-Matos, C. (2008). Soil vapor extraction in sandy soils: influence of airflow rate. Chemosphere, 73, 1557-1561.

Albergaria, J. T., Alvim-Ferraz, M. D. M., \& Delerue-Matos, C. (2012). Remediation of sandy soils contaminated with hydrocarbons and halogenated hydrocarbons by soil vapour extraction. Journal of Environmental Management, 104, 195-201.

Albergaria, J. T., Alvim-Ferraz, M. D. M., \& Delerue-Matos, M. C. F. (2010). Estimation of pollutant partition in sandy soils with different water contents. Environmental Monitoring and Assessment, 171, 171-180.

Alvim-Ferraz, M. C. M., Albergaria, J. T., \& Delerue-Matos, C. (2006). Soil remediation time to achieve clean-up goals I: influence of soil water content. Chemosphere, 62, 853-860.

Atlas, R. M., \& Bartha, R. (1998). Microbial ecology: fundamentals and applications (4th ed.). Redwood City: Benjamin Cummings.

Beskoski, V.P., Gojgic-Cvijovic, G., Milic, J., Ilic, M., Miletic, S., Solevic, T., et al. (2011). Ex situ bioremediation of a soil contaminated by mazut (heavy field experiment. Chemosphere, 83, 34-40.

Braddock, J. F., Ruth, M. L., Catterall, P. H., Walworth, J. L., \& McCarthy, K. A. (1997). Enhancement and inhibition of microbial activity in hydrocarbon-contaminated arctic soils: implications for nutrient-amended bioremediation. Environmental Science and Technology, 31, 2078-2084.

Cameotra, S. S., \& Makkar, R. S. (2010). Biosurfactantenhanced bioremediation of hydrophobic pollutants. Pure and Applied Chemistry, 82, 97-116.

Carroll, K. C., Oostrom, M., Truex, M. J., Rohay, V. J., \& Brusseau, M. L. (2012). Assessing performance and closure for soil vapor extraction: integrating vapor discharge and impact to groundwater quality. Journal of Contaminant Hydrology, 128, 71-82.

El Fantroussi, S., \& Agathos, S. N. (2005). Is bioaugmentation a feasible strategy for pollutant removal and site remediation? Current Opinion in Microbiology, 8, 268-275.

Gentry, T. J., Rensing, C., \& Pepper, I. L. (2004). New approaches for bioaugmentation as a remediation technology. Critical Reviews in Environmental Science and Technology, 34, 447-494.

Jacques, R. J. S., da Silva, K. J., Bento, F. M., \& Camargo, F. A. D. (2010). Bioremediation of a soil contaminated with anthracene under different chemical and physical conditions. Ciência Rural, 40, 310-317.

Jiao, L. N., Zhao, Y.S., Qu, Z. H., \& Wang, B. (2011). Study on influencing factors on removal of diesel oil from unsaturated zone by soil vapor extraction. In Q. Luo \& Y.Z. Wang (Eds.), Advanced materials science and technology, Pts 1-2 (pp. 401-405). Stafa, Zurich: Trans Tech Publications Ltd.

Kaleris, V., \& Croise, J. (1997). Estimation of cleanup time for continuous and pulsed soil vapor extraction. Journal of Hydrology, 194, 330-356. 
Kelly, D. P., Baker, S. C., Trickett, J., Davey, M., \& Murrell, J. C. (1994). Methanesulfonate utilization by a novel methylotrophic bacterium involves an unusual monooxygenase. Microbiology, 140, 1419-1426.

Kirtland, B. C., \& Aelion, C. M. (2000). Petroleum mass removal from low permeability sediment using air sparging/ soil vapor extraction: impact of continuous or pulsed operation. Journal of Contaminant Hydrology, 41, 367-383.

Macci, C., Doni, S., Peruzzi, E., Ceccanti, B., \& Masciandaro, G. (2012). Bioremediation of polluted soil through the combined application of plants, earthworms and organic matter. Journal of Environmental Monitoring, 14, 2710-2417.

Menendez-Vega, D., Gallego, J. L. R., Pelaez, A. I., de Cordoba, G. F., Moreno, J., Munoz, D., et al. (2007). Engineered in situ bioremediation of soil and groundwater polluted with weathered hydrocarbons. European Journal of Soil Biology, 43, 310-321.

Moliterni, E., Rodriguez, L., Fernandez, F. J., \& Villasenor, J. (2012). Feasibility of different bioremediation strategies for treatment of clayey and silty soils recently polluted with diesel hydrocarbons. Water, Air, and Soil Pollution, 223, 2473-2482.

Qin, C. Y., Zhao, Y.S., Zheng, W., \& Li, Y.S. (2010). Study on influencing factors on removal of chlorobenzene from unsaturated zone by soil vapor extraction. Journal of Hazardous Materials, 176, 294-299.

Qin, X., Tang, J. C., Li, D. S., \& Zhang, Q. M. (2012). Effect of salinity on the bioremediation of petroleum hydrocarbons in a saline-alkaline soil. Letters in Applied Microbiology, $55,210-217$.
Soares, A. A., Albergaria, J. T., Domingues, V.F., Alvim-Ferraz, M. D. M., \& Delerue-Matos, C. (2010). Remediation of soils combining soil vapor extraction and bioremediation: benzene. Chemosphere, 80,823-828.

Soares, A. A., Pinho, M. T., Albergaria, J. T., Domingues, V., Alvim-Ferraz, M. D. M., De Marco, P., et al. (2012). Sequential application of soil vapor extraction and bioremediation processes for the remediation of ethylbenzenecontaminated soils. Water, Air, and Soil Pollution, 223, 2601-2609.

Suthersan, S. S. (1999). Soil vapor extraction. In S. S. Suthersan (Ed.), Remediation engineering: design concepts (pp. 2788). Boca Raton: Lewis Publisher Inc.

Environmental Protection Agency (USEPA). (1997). Analysis of selected enhancements for soil vapor extraction. Washington, DC: Office of Solid Waste and Emergency Response.

United States Environmental Protection Agency (USEPA). (2010). Superfund Remedy Report. Washington, D.C.: USEPA.

Yin, F. X., Zhang, S. T., Zhao, X., Feng, K., \& Lin, Y. S. (2011). Removal of volatile organic compounds in soils by soil vapor extraction (SVE). Environmental Science and Technology, 32, 1454-1461.

Yoon, H., Valocchi, A. J., \& Werth, C. J. (2003). Modeling the influence of water content on soil vapor extraction. Vadose Zone Journal, 2, 368-381.

Zhang, Q., Wang, B. C., Cao, Z. Y., \& Yu, Y. L. (2012). Plasmid-mediated bioaugmentation for the degradation of chlorpyrifos in soil. Journal of Hazardous Materials, 221, 178-184. 